AperTO - Archivio Istituzionale Open Access dell'Università di Torino

\title{
Liver Sinusoidal Endothelial Cells at the Crossroad of Iron Overload and Liver Fibrosis
}

\section{This is the author's manuscript}

Original Citation:

Availability:

This version is available http://hdl.handle.net/2318/1761876

since 2021-07-27T13:44:50Z

Published version:

DOI:10.1089/ars.2020.8168

Terms of use:

Open Access

Anyone can freely access the full text of works made available as "Open Access". Works made available under a Creative Commons license can be used according to the terms and conditions of said license. Use of all other works requires consent of the right holder (author or publisher) if not exempted from copyright protection by the applicable law. 
FORUM REVIEW ARTICLE

\section{Liver Sinusoidal Endothelial Cells at the crossroad of Iron overload and Liver Fibrosis}

Sara Petrillo ${ }^{1 \star}$, Marta Manco $^{1 \star}$, Fiorella Altruda $^{1}$, Sharmila Fagoonee ${ }^{2}$, Emanuela Tolosano $^{1^{\circ}}$

${ }^{1}$ Molecular Biotechnology Center, Department of Molecular Biotechnology and Health Sciences, University of Torino, Via Nizza 52, 10126 Torino, Italy

2 Institute of Biostructure and Bioimaging, CNR c/o Molecular Biotechnology Center, Torino, Italy

* SP and MM contributed equally to this work.

- SF and ET contributed equally to this work.

Emanuela Tolosano

Molecular Biotechnology Center, Department of Molecular Biotechnology and Health

Sciences, University of Torino, Via Nizza 52, 10126 Torino, Italy

Phone: +390116706423

emanuela.tolosano@unito.it

Word count (excluding references and figure legends): 5312

Reference numbers: 128

Number of greyscale illustrations: 0

Number of color illustrations: 6 (online 6)

(If color illustrations are for online only, indicate that in parentheses [e.g., Color illustration: 3 (online 1 and hardcopy 2)])

Manuscript keywords (search terms): Iron, LSEC, liver fibrosis, sinusoidal endothelial cells

Running title: Iron, LSEC and liver fibrosis 


\begin{abstract}
Significance Liver fibrosis results from different etiologies and represents one of the most serious health issues worldwide. Fibrosis is the outcome of chronic insults on the liver and is associated with several factors, including abnormal iron metabolism.

Recent Advances Multiple mechanisms underlying the pro-fibrogenic role of iron have been proposed. The pivotal role of Liver Sinusoidal Endothelial Cells (LSECs) in iron level regulation, as well as their morphological and molecular de-differentiation occurring in liver fibrosis, have encouraged research on LSECs as prime regulators of very early fibrotic events. Importantly, normal differentiated LSECs may act as gatekeepers of fibrogenesis by maintaining the quiescence of Hepatic Stellate Cells (HSCs), while LSECs capillarization precedes the onset of liver fibrosis.
\end{abstract}

Critical Issues In the present review, the morphological and molecular alterations occurring in LSECs following liver injury are addressed in an attempt to highlight how vascular dysfunction promotes fibrogenesis. In particular, we discuss in depth how a vicious loop can be established in which iron-dysregulation and LSEC de-differentiation synergize to exacerbate and promote the progression of liver fibrosis.

Future Directions LSECs, due to their pivotal role in early liver fibrosis and iron homeostasis, show great promises as a therapeutic target. In particular, new strategies can be devised for restoring LSECs differentiation and thus their role as regulators of iron homeostasis, hence preventing the progression of liver fibrosis or, even better, promoting its regression.

Petrillo S, Manco M 


\section{Introduction}

Liver diseases are a major health problem worldwide and it has been estimated that 2 million deaths occur per year due to cirrhosis, viral hepatitis and liver cancer (5). Liver fibrosis, characterized by the excessive deposition of extracellular matrix (ECM), is the hallmark of several liver diseases of different etiology and it is frequently associated or preceded by abnormal iron accumulation (82). Interestingly, systemic iron homeostasis is mainly orchestrated by the liver itself through the production of the peptide hormone hepcidin, which can regulate plasma iron homeostasis upon several stimuli including iron, inflammation and hypoxia $(42,89,95,100)$. The role of iron in liver injury has been recently reviewed $(11,82)$. Here, we focus on one of the important cellular components of the liver involved in fibrogenesis, the Liver Sinusoidal Endothelial Cells (LSECs). In particular, we review the morphological and molecular alterations occurring in LSECs at early stages of the fibrotic process and highlight the pivotal role these cells play in the regulation of both serum iron and tissue iron. Finally, we discuss the relationship between LSECs de-differentiation and liver fibrosis-related iron overload.

\section{Liver fibrosis}

The liver is the largest internal organ of the human body and performs several vital functions, such as [1] acute phase proteins synthesis, [2] detoxification, [3] carbohydrate and lipid metabolism and [4] bile production $(36,112)$. Liver injury triggers a wound healing response, namely fibrogenesis, involving [1] the recruitment of immune and/or inflammatory cells, [2] the secretion and reorganization of extracellular matrix (ECM) proteins and [3] hepatic regeneration (9). However, if the harmful stimulus is not promptly removed, an uncontrolled wound healing response occurs. Necrotic hepatocytes are gradually substituted by excessive ECM deposits (i.e. fibrosis) in liver parenchyma, thus disrupting its architecture and, consequently, interfering with its normal functionality. For this reason, untreated Chronic Liver 
Diseases (CLDs) are characterized by fibrosis that progressively leads to the more severe clinical conditions of cirrhosis and hepatocellular carcinoma (38). Different etiologies can trigger and sustain fibrotic changes in the liver. Consistently, several diseases are associated with a high risk of fibrosis, such as Viral Hepatitis, Alcoholic Liver Disease, Non-Alcoholic Fatty Liver Disease (NAFLD), Non-Alcoholic Steatohepatitis (NASH), Diabetes and Hereditary Hemochromatosis $(\mathrm{HH})$, a disorder characterized by iron overload (Figure 1) (82).

Fibrogenesis is a dynamic process, which involves different cell populations and a wide range of injury-dependent molecular mechanisms. At the histological level, liver fibrosis is characterized by fibrous septa, which progressively thicken and extend leading to the formation of bridges between the portal tract and the central vein (porto-central fibrosis), among portal tracts (porto-portal fibrosis) or in the perisinusoidal space (perisinusoidal fibrosis) (17). Different liver cell populations are involved in fibrogenesis. The Hepatic Stellate Cells (HSCs), located in the space of Disse around the sinusoids, are mainly responsible for perisinusoidal fibrosis following activation and myofibroblastic transformation. HSCs, as the major producers of ECM, are the most studied cell type in the fibrotic process. On the other hand, the portal myofibroblasts have been implicated the development of portal fibrosis. However, besides HSCs and portal myofibroblasts, two other non-parenchymal cellular components, situated in the sinusoidal compartment of the liver, are involved in fibrogenesis: Kupffer cells and LSECs. In particular, Kupffer cells are the resident liver macrophages with panoply of functions ranging from maintaining homeostasis to controlling inflammation and repair upon injury $(12,111)$. Kupffer cells participate in the early response to injury by rapidly releasing cytokines and chemokines (e.g. IL-1 $\beta$ and CCL2, respectively), which further induce the recruitment of other immune cells. The immune cells can then decide the fate of the liver, either by promoting liver injury, such as the Ly-6Chi monocytes bearing pro-inflammatory and pro-fibrogenic activity, or by stimulating injury resolution through the Ly-6Clow phenotype (111). On the other hand, LSECs constitute the lining of the hepatic sinusoids (58). They perform 
important filtration and endocytic functions, may act as antigen-presenting cells and secrete cytokines, eicosanoids, endothelin-1, nitric oxide and some ECM components (58). Over the years, it has been widely demonstrated that chronic liver injury leads to distinct morphological abnormalities such as loss of sinusoidal fenestration, vasoconstriction and aberrant angiogenesis, as well as molecular changes in different liver cell populations (47). Importantly, alterations in the hepatic sinusoidal microenvironment are among the first events to occur following injury, thus contributing to the onset and progression of liver fibrosis. For this reason, pharmacological inhibition of these changes, especially in LSECs, has become one of the leading strategies for anti-fibrotic drug development (68).

\section{Iron and liver fibrosis}

Iron in liver diseases: the cause or the consequence?

Hitherto, the exact cellular and molecular mechanisms underlying the onset and the progression of liver fibrosis are still not fully understood. Nevertheless, iron is an attractive candidate. In fact, it has been postulated that iron, through multiple mechanisms, exerts a profibrogenic role (82). Evidence suggesting that high iron levels could be involved in the pathogenesis of liver fibrosis derives from studies on diseases characterized by iron dysregulation (40). For instance, progressive liver fibrosis is the major comorbidity and the main cause of death in patients affected by $\mathrm{HH}(40) . \mathrm{HH}$ is an inherited disorder of abnormal iron metabolism, due to the lack of or resistance to the iron hormone hepcidin (57). Consistently, patients affected by $\mathrm{HH}$ exhibit excessive amount of body iron, which, in turn, induces multi-organ injury (e.g. in the liver, pancreas and heart) $(40,57)$. Whilst the cellular and molecular mechanisms are still under investigation, it is well established that liver iron content correlates with hepatic fibrosis in $\mathrm{HH}$ patients. Over the years, multiple mechanisms 
underlying the pro-fibrogenic role of iron have been proposed $(24,103)$ and some of these will be discussed in-depth below.

As stated above, HSCs are the most studied cell type in the fibrotic process, due to their pivotal role in the synthesis and the deposition of ECM. Interestingly, several studies showed that iron promotes the activation of HSCs (103). In particular, high iron levels within the liver may damage hepatocytes and Kupffer cells through oxidative stress-dependent mechanisms $(24,99)$. The damaged cells, in turn, begin to secrete pro-inflammatory and profibrogenic factors (e.g. TGF- $\beta$ ), thus triggering liver inflammation and, most importantly, HSCs activation $(24,103)$. These data highlighted the importance of both cell-to-cell communication and iron-oxidative stress axis in the pathogenesis of liver fibrosis (Figure 2). Consistently, defective antioxidant defenses, due to genetic disruption of Nuclear factor erythroid 2-Related Factor 2 (NRF2), promoted the transition from iron accumulation to liver fibrosis in a mouse model of $\mathrm{HH}$ (35). Moreover, recent studies have suggested that HSCs, once activated, become responsive to iron by starting to express Transferrin Receptor 1 (TFR1) and H-ferritin receptor on their surface $(15,81,82,102,109)$.

However, other evidence has led researchers to question whether iron overload is the cause or can also be a consequence of CLDs and liver fibrosis. Indeed, iron metabolism dysregulation has been reported in patients with CLDs in the absence of a $\mathrm{HH}$-associated genotype $(11,64)$. Consistently, a high number of HCV patients $(20-40 \%)$ display elevated serum iron parameters, namely transferrin saturation, serum iron and ferritin levels (31). Abnormalities in serum iron parameters have also been found in subjects with NASH (44). These data, taken together, indicate that iron metabolism dysregulation is frequently observed in patients with CLD, regardless of etiology. Hence, it is reasonable that dysregulation of iron metabolism may arise consequently to a chronic liver disease. Notably, transferrin and ferritin are considered a negative and a positive acute-phase reactant, respectively $(48,113)$. Hence, the serum levels of these proteins are modulated not only in response to iron but also to 
inflammation or liver damage. Nevertheless, despite different mechanisms can contribute to abnormal transferrin and ferritin serum levels, patients with CLDs exhibit also low hepcidin serum levels $(37,69,114)$. Importantly, iron metabolism dysregulation, which arises secondary to a CLD, may accelerate the progression of liver fibrosis to cirrhosis and to hepatocellular carcinoma, due to iron pro-inflammatory and pro-fibrogenic properties. Literature-based evidence supports this speculation in both humans and rodents. For instance, Abe et al. recently showed that the dietary iron restriction in a rat model of NASH leads to a reduction in [1] the hepatic iron content, [2] oxidative stress, [3] inflammation and [4] hepatic fibrosis (1). Furthermore, aside from its role in accelerating the progression of earlystage CLDs, iron negatively affects the outcome of patients with an end-stage CLDs $(22,55$, 63). In particular, since iron is an essential element for most microorganisms, iron overload may increase the risk of infections, and even death, following liver transplant. Consistently, $\mathrm{HH}$ patients with mutations in HFE gene, a key interactor of both TFR1 and TRF2 $(21,43)$, display iron overload and reduced survival after liver transplant (64). Ko et al. also highlighted a strong correlation between hepatic iron content and hepatocellular carcinoma, probably due to the role of iron in inducing DNA damage (60).

Overall, it is clear that iron overload, frequently observed in multiple CLDs, could have important clinical implications. However, even though CLD patients exhibit low serum hepcidin levels, the exact molecular mechanisms underlying iron overload in CLDs are still elusive. For this reason, it is of paramount importance to further address this issue in an attempt to open new windows of intervention. Along this line, several studies (discussed below) have indicated that LSECs play a key role both in the pathogenesis of liver fibrosis and in the regulation of hepcidin expression and, consequently, in the control of iron levels.

\section{LSECs and liver fibrosis}

LSECs: structure, function and molecular signature 
Endothelial cells (ECs) have long been considered as passive cells delimiting blood vessels. However, in the last few years, a considerable number of studies have shown that ECs are, instead, actively involved in organ development, regeneration and homeostasis maintenance $(6,25,65,77)$. Furthermore, it is becoming increasingly clear that, at the basis of many chronic and life-threatening diseases (e.g. metabolic disorders, atherosclerosis and cancer), there is vascular dysfunction, emphasizing once again the importance of ECs in ensuring a proper organ and, consequently, body physiological function (45). In this regard, microvascular ECs undergo a process of organ-specific specialization and differentiation, i.e. vascular organotypicity (6). In our body, there are three major types of capillaries with a different grade of permeability and molecular transport (from the lowest to the highest): continuous, fenestrated and sinusoidal. Moreover, the morphological classification of capillaries is associated to a unique gene expression profile, and in particular, to a unique array of organ-specific angiocrine signals, i.e. ECs-derived paracrine factors dictating the microenvironment behavior $(6,16)$.

LSECs, lining the hepatic sinusoids, are liver-specific differentiated microvascular ECs, and represent about $19 \%$ of total liver cells (90). LSECs, despite falling into the category of sinusoidal capillaries with spleen and bone marrow ECs, can be regarded as unique due to the presence of open (non-diaphragmed) fenestrae and the lack of a typical basement membrane. Thus, LSECs do not represent a barrier for macromolecule transport as ECs in other organs but allow a bidirectional "open" solute exchange between blood and hepatocytes. Thanks to the pioneering work of Wisse (119) in 1970 and subsequent reports by Widmann (118) and Ogawa (93), LSECs fenestrae are considered as transcellular open pores of approximately $100-150 \mathrm{~nm}$ in size clustered in groups- the so-called sieve plates, thus occupying around $6-8 \%$ of the endothelial surface. Successively, it emerged that the fenestration pattern (frequency and diameter of fenestrae) is not uniform across liver lobule but changes from the periportal to the centrilobular zone: bigger but fewer fenestrae per sieve 
plate to smaller but more numerous fenestrae per sieve plate, respectively $(121,123)$. Ultrastructural analysis of hepatic sinusoids, and specifically of LSECs, aside from fenestrae, revealed a large number of bristle-coated micropinocytotic vesicles and lysosome-like vacuoles, thus suggesting that LSECs have a high endocytic capacity (120). Overall, LSECs [1] act as a sieve, by filtering in a "passive and size-selective manner" virus, solutes and particles (e.g. chylomicron remnants) smaller than the fenestrae diameter from and to the space of Disse, and [2] have a scavenger function, by actively supporting the uptake and degradation of a diverse array of macromolecules $(13,110)$.

Despite these findings, several aspects of the LSEC biology remain unclear, for instance, regarding the molecular and structural mechanisms underlying the formation, maintenance and dynamic regulation of their fenestrae. This is because one of the major challenges in studying LSECs, besides the lack of specific markers for identifying differentiated LSECs or technical and methodological limitations due to the small diameter of fenestrae, is the lack of a good and reliable in vitro cellular model. In fact, upon isolation from the hepatic microenvironment, LSECs lose their unique morphological and functional features within very few days in culture (29). Interestingly, new cell culture systems recapitulating the complex hepatic microenvironment (e.g. co-culture and microfluidic chip) have been developed to overcome this drawback. Several groups examined the effects of extracellular matrix and neighboring cells on LSEC phenotype in vitro $(33,41,54,72,79)$. They demonstrated that LSECs undergo a microenvironment-dependent differentiation program mainly orchestrated by the Vascular Endothelial Growth Factor (VEGF). In particular, DeLeve et al. showed that VEGF produced by HSCs regulates LSEC phenotype by stimulating Nitric Oxide (NO) production (29). Thus, the maintenance of LSECs fenestration needs both paracrine and autocrine signaling.

At the molecular level, angiodiversity remains scarcely characterized. Lately, great efforts have been made to deeply unravel the heterogeneity of organ-specific microvascular 
ECs molecular signatures $(50,73,92)$. To identify the LSEC-specific molecular differentiation program, Géraud et al. performed a cDNA microarray analysis comparing freshly isolated LSECs with both Lung Microvascular Endothelial Cells (LMECs), as common continuous ECs, and LSECs cultured for 42 hours (which undergo spontaneous dedifferentiation) (50). Importantly, a microenvironment-dependent LSEC-specific repertoire of cytokines and growth factors (Wnt2, Wls, Nrp2), transcriptional regulators (Gata4, Lmo3, Maf, Tcfec) and scavenger- and endocytosis-related genes (Stab1/2, Lyve1 and Ehd3) was found (50). Later on, the same authors analyzed the role of one of LSEC-associated transcription factor, GATA4, in driving liver-specific microvascular transcriptional program. By performing both in vitro and in vivo experiments, they demonstrated that GATA4 is essential for a proper LSEC phenotype and directly regulates most of the LSEC-associated genes, thus acting as the master regulator of hepatic microvascular specialization (49). Furthermore, the authors showed that LSEC-specific GATA4 deletion in mice is sufficient to induce [1] lethal embryonic anemia due to impaired liver colonization of hematopoietic progenitor cells, [2] liver hypoplasia and [3] liver fibrosis (49). Thus, this evidence further heightens the importance of LSECs fenestration in ensuring proper liver development and the pivotal role of vascular dysfunction in triggering liver fibrosis.

Among the GATA4-regulated and LSEC-specific genes, the Bone Morphogenetic Proteins (BMP) 2 gained particular attention $(49,50,94)$. As further discussed below, several experimental evidence shows that LSECs, by producing BMP2 and BMP6, play an important role in the regulation of iron homeostasis $(18,19,61,104)$.

\section{LSECS capillarization and liver fibrosis}

As mentioned before, LSECs are considered unique ECs for their open fenestrae and disorganized basement membrane. Interestingly, despite their high specialization, LSECs retain considerable phenotypic and functional plasticity. In fact, LSECs fenestrae are dynamic 
structures with their number and diameter capable of changing over time in the hepatic vascular beds in response to external stimuli (13).

The loss of fenestration and deposition of an organized sub-endothelial basement membrane is called "capillarization" (107). LSECs de-differentiation or sinusoidal capillarization is now considered a hallmark of liver fibrosis and cirrhosis, regardless of the cause $(27,51,74,101,126)$. For example, Miyao et al. showed that Scanning Electron Microscopy (SEM) analysis of livers derived from mice fed with two different fibrogenic diets (DDC-supplemented diet and CDAA diet) presented, already at very early time-points, sinusoidal capillarization $(84,85)$.

Due to the crucial role of LSECs fenestration in liver physiology, its alteration could compromise parenchyma function, thus contributing to liver fibrosis onset and to hepatic failure and related complications, i.e. portal hypertension, gradually leading to cirrhosis. Consistently, several studies performed both on human samples and animal models demonstrated that normal differentiated LSECs act as gatekeepers of fibrogenesis by maintaining the quiescence of HSCs $(28,59,124,128)$ and that LSECs capillarization precedes the onset of liver fibrosis $(34,49,124)$. Moreover, de-differentiated (i.e. without open fenestrae) LSECs [1] contribute to ECM deposition through the production of collagen and fibronectin $(88,125)$, [2] promote portal hypertension $(46,78,105)$, [3] participate in the generation of the inflammatory milieu, and [4] alter intrahepatic immunity $(23,80)$ (Figure 3).

In addition to structural alterations, during the fibrotic process, LSECs undergo a dramatic change in their expression profile. In fact, it was shown that GATA4 decreased considerably during human and rodent liver fibrogenesis $(30,115)$. This evidence further heightens the involvement of GATA4 in orchestrating LSEC phenotype as well as the close association between LSECs morphology and their molecular signature. In fact, dedifferentiated LSECs switch on the expression of genes commonly-associated to EC, such as CD31 and CD34, at the expense of LSEC-associated genes, such as GATA4, STAB1/2, 
GPR182 and LYVE1 $(32,34,108,115)$. This gene expression shift has a negative impact also on liver-specific angiocrine signals repertoire, e.g. WNT2 and BMP2. All these works further highlight the importance of counteracting LSEC fenestration loss in order to prevent and/or slow-down the fibrogenic process.

\section{LSECs and iron metabolism}

\section{LSECs regulate serum and tissue iron homeostasis}

As discussed above, dysregulated iron metabolism can exacerbate the pathogenesis of fibrosis and cirrhosis in the liver due to the pro-inflammatory and pro-fibrogenic properties of iron. Multiple liver cell types contribute to determine serum iron levels by participating in iron uptake, utilization, recycling and storage. All these processes must be finely coordinated to keep iron levels within a physiological range, thus avoiding the onset of iron-related disorders(53). Importantly, recent findings suggest that LSECs, by finely communicating with hepatocytes, play a pivotal role in the coordination of these processes and in the maintenance of serum and tissue iron homeostasis. To this end, hepcidin, a peptide hormone encoded by the HAMP gene and secreted by hepatocytes, controls the release of iron from the cell into the circulation $(91,100)$. Hepcidin regulates the activity of different cell types including [1] the enterocytes, which mediate dietary iron absorption in the intestine; [2] the macrophages, responsible for the recycling of iron derived from erythrocytes' turnover; and [3] the hepatocytes, major site of iron storage $(86,89,95,100)$. At molecular level, hepcidin exerts its regulatory activity by binding the iron-exporter Ferroportin (FPN) on the surface of target cells and mediating its endocytosis and degradation, thus preventing the entry of iron into the blood (Figure 4). Hepcidin expression is directly modulated by the body iron status through mechanisms that involve the BMP-SMAD signaling pathway $(7,8,14,20,96,116)$. BMPs belong to the Transforming Growth Factor- $\beta$ (TGF- $\beta$ ) superfamily that includes over 30 known secreted factors $(75,117)$. Among them, only BMP6 and, more recently, BMP2 have been 
identified as key regulators of hepcidin expression, as demonstrated by murine knockout studies and genetic analysis of patients with iron overload $(4,26,96,97)$. In particular, total BMP6 loss in mice results in a strong reduction in hepcidin expression and increased tissue iron accumulation, a phenotype resembling hereditary hemochromatosis (4). The interaction of BMPs with their type I and type II receptors on hepatocyte surface leads to the phosphorylation of SMAD1/5/8 proteins, which, after complexing with SMAD4, translocate to the nucleus, bind the hepcidin promoter and activate its expression $(7,76,116)$. However, the capability of relevant BMPs to fully activate BMP-SMAD signaling pathway strictly depends on the presence of the co-receptor Hemojuvelin (HJV) on hepatocyte surface $(7,8,62,66$ ). Consistently, BMP(s)-dependent hepcidin induction is inhibited by the serine protease Matriptase-2 (encoded by TMPRSS6 gene), that is responsible for HJV cleavage $(3,39,87)$. In support of the key role of Matriptase-2 in preventing inappropriate activation of BMP-SMAD signaling, it was shown that mutations in the TMPRSS6 gene were associated to a condition of Iron-Refractory Iron-Deficiency Anemia (IRIDA) in human patients, caused by persistent hepcidin induction (87).

Importantly, while hepcidin and Matriptase-2 show a hepatocyte-restricted expression, BMP6 mRNA levels have been detected at higher levels in liver NPCs compared to hepatocytes $(104,127)$. Studies utilizing conditional knockout mice led to the identification of LSECs as primary source of BMP6. In particular, Canali et al. showed that mice with a conditional knockout of BMP6 in LSECs exhibited significantly reduced liver hepcidin mRNA and, consequently, increased serum and tissues iron loading, thus resembling the phenotype of total BMP6 null mice (19). Conversely, BMP6 conditional deletion in Kupffer cells or in hepatocytes did not alter hepcidin expression or serum and tissues iron content (19). These studies pointed out the pivotal role of LSECs in the modulation of hepatic hepcidin mRNA expression and identified BMP6 as a key angiocrine factor involved in iron regulation. However, the specific signals that trigger BMP6 production in LSECs are still under 
investigation. Recent findings showed that BMP6 expression is regulated by the transcription factor NRF2 in response to iron-induced oxidative stress (70). Interestingly, BMP6 loss in combination with HFE or TFR2 loss, both involved in $\mathrm{HH}$, results in a more severe phenotype compared to single BMP6-deficient mice, with decreased SMAD5 phosphorylation and further repression of Hamp gene expression (67). Moreover, BMP6-null mice retain a residual ability to induce hepcidin through SMAD signaling upon iron stimulation, thus suggesting that, in the absence of BMP6, other mechanisms could occur. Some studies investigated the possible involvement of other BMPs in the regulation of hepcidin transcription. BMP2, a GATA4regulated and LSEC-specific angiocrine signal, emerged as a promising candidate. Indeed, in vitro studies on freshly isolated murine primary hepatocytes revealed that Holo-Transferrin treatment leads to an increase in hepcidin mRNA levels through a HJV/BMP2/4-dependent pathway (71). Moreover, a Single Nucleotide Polymorphism (SNP) of the BMP2 gene region, found in a cohort of human patients with hemochromatosis, has been associated to the severity of iron loading (83). A resolutive evidence of BMP2 involvement in hepcidin regulation comes from the generation of LSEC-specific conditional BMP2-null mice $(18,61)$. In particular, genetic inactivation of BMP2 in LSECs leads to a strong reduction in hepcidin expression, that in turn causes liver and tissues iron accumulation and increased serum iron levels, similar to the phenotype of LSEC-specific BMP6-null mice (61).

These data, taken together, strongly demonstrate the paramount role of endothelial BMP2 and BMP6 in the regulation of hepcidin transcription. However, the relative contribution of these two BMPs in activating SMAD pathway and, consequently, in stimulating hepcidin, remains uncertain. An important hint came from the study of Canali et al., which essentially demonstrated that the residual ability to induce hepcidin upon iron stimulation in BMP6-null mice was lost following treatment with a neutralizing BMP2/4 antibody (18). This observation suggests that BMP2 and BMP6 work independently in activating hepcidin transcription. Nevertheless, the severity of the disease in both endothelial-specific BMP6- and BMP2-null 
mice indicates that none of these factors can fully compensate for the absence of the other. Consistently, the up-regulation of Bmp6 observed in mice lacking BMP2 in endothelial cells was not sufficient to mitigate their iron overload phenotype (18). Moreover, Xiao et al. recently showed that iron overload phenotype is not exacerbated in the double knockout of BMP2/6 compared to single BMP2 or BMP6 knockout (122). Hence, BMP2 and BMP6 may cooperate to regulate hepcidin expression and could be activated by different stimuli or act through different mechanisms. Notably, it has been shown that LSECs, under basal condition, mainly express Bmp2 (that is, higher Bmp2 mRNA copy number compared to Bmp6) but exhibit an iron overload-mediated positive regulation of Bmp6 at a greater extent than Bmp2 (18). Consistently, it may be hypothesized that BMP2 is important in conditions of basal/low iron, while BMP6 takes over when iron level increases. Furthermore, since BMPs can form both homodimers and heterodimers with a different (lower and higher, respectively) affinity for type I/type II receptors (56), it has been also proposed that BMP6 and BMP2 might work as a complex to induce hepcidin expression. Likewise, in the absence of BMP2, for example, homodimers of BMP6 (with a lower affinity for the receptors) are not able to sufficiently activate hepcidin expression and to fully compensate for the lack of BMP2. Accordingly, Canali et al. hypothesised that the inability of BMP6 to mitigate the iron overload phenotype due to BMP2 loss in endothelial cells, could be related to its inability to form BMP2/BMP6 heterodimers (18).

Despite the still open questions regarding hepcidin regulation, LSECs have proved to be fundamental regulators of systemic iron homeostasis, mainly through the production of the angiocrine factors BMP2 and BMP6 (Figure 5).

\section{LSECs, iron dysregulation and liver fibrosis}

As previously discussed, low hepcidin serum levels, and consequently, iron overload, are common features in patients with CLDs, even in the absence of mutations in 
hemochromatosis-related genes. However, the exact molecular mechanisms underlying the link between liver diseases and iron are still largely unknown.

The recent findings about the pivotal role of LSECs in iron level regulation, their morphological and, most importantly, molecular de-differentiation in liver fibrosis, prompted researchers to investigate the possible relationship between LSECs de-differentiation and liver fibrosis-related iron overload. It has been shown that cirrhotic liver-derived de-differentiated LSECs express Bmp2 at lower levels compared to normal liver-derived fenestrated LSECs (115). Therefore, in the absence of BMP2, hepcidin synthesis and secretion may be inadequate. Moreover, Hasebe et al. recently described a possible mechanism underlying NAFLD-associated iron dysregulation (52). In particular, mice fed with a high-fat diet to induce NAFLD, exhibited low serum levels of hepcidin, and consequently, iron overload both in serum and in the liver. RNA sequencing analysis, performed on whole livers of these mice versus controls, revealed 36 dysregulated iron metabolism-related genes, including BMP-binding Endothelial Regulator (BMPER). Consistently, mice fed a high-fat diet exhibited higher Bmper expression levels in the liver, as well as an increasing trend of plasma level of BMPER, which co-immunoprecipitated with BMP6. Moreover, BMPER was found strongly expressed by LSECs in the fatty/fibrotic liver (52). As previously demonstrated, a soluble form of BMPER suppresses BMP2- and BMP6-dependent hepcidin induction by binding and sequestering extracellular BMPs (98). Although there are no hints on the differentiation status of LSECs, these findings suggest that LSECs-released BMPER could impair BMPs signaling, thus reducing hepcidin expression in fatty/fibrotic livers. Hence, it can be postulated that at the basis of liver fibrosis-associated iron overload, there may be vascular dysfunction, which compromises the BMP(s)-hepcidin axis between LSECs and hepatocytes. Since altered serum iron parameters (e.g. transferrin saturation) are important drivers of liver fibrosis progression, it is of great importance to further investigate whether there is a causative association between de-differentiated LSECs and serum iron levels in liver fibrosis. 
Another layer of complexity derives from the evidence that iron itself can induce the shift from sinusoidal to continuous ECs (i.e. LSECs capillarization). Addo et al. demonstrated that iron overload stimulates the hepatocytes to produce and secrete Nerve Growth Factor (NGF), which in turn can induce LSECs defenestration (2). Moreover, recent findings suggest that iron may also be able to directly and negatively affect LSEC phenotype. In particular, Lim et al. showed that iron, by promoting mitochondrial oxidative damage, activates the transcription factor NRF2, as a protective response in LSECs (70). Nevertheless, a persistent activation of NRF2 has been reported to inhibit autophagy and, since autophagy has a protective role in maintaining LSECs integrity and phenotype (i.e. fenestrae), iron-induced NRF2 activity may contribute to endothelial dysfunction $(10,106)$. Thus, even if further experiments are needed to validate these points, it could be hypothesized that in the liver fibrosis context, often characterized by iron accumulation, a vicious circle may exist through which de-differentiated LSECs induce iron overload, which in turn may directly and indirectly maintains and perpetuates LSECs capillarization over time, thus exacerbating liver fibrosis (Figure 6).

\section{Conclusions}

Liver fibrosis represents a major world health problem due to the lack of therapeutic treatments as alternatives to liver transplantation. Due to their contribution to not only the onset and progression of liver fibrosis but also to iron homeostasis regulation, LSECs emerged as a promising and attractive therapeutic target. An early event of the fibrotic process is the loss of fenestrae in the hepatic sinusoids due to progressive de-differentiation of LSECs, a phenomenon referred to as "LSECs capillarization". Importantly, de-differentiated LSECs undergo a dramatic change in the repertoire of secreted angiocrine factors. Some of these factors likely contribute to determine a condition of iron overload in the fibrotic liver. Nevertheless, iron overload itself has been reported to promote LSEC de-differentiation. 
These findings, taken together, indicate that, in CLDs, a vicious loop can be established in which iron-dysregulation and LSEC de-differentiation synergize to exacerbate and promote the progression of liver fibrosis.

Considering the data and evidence gathered in this emerging research field, it is worth spending great efforts to develop new therapeutic strategies aimed at restoring LSECs differentiation and, consequently, at preventing the progression of liver fibrosis or, even better, at promoting its regression. 


\section{Acknowledgments}

We thank Marta Gai for the helpful discussion.

This work was supported by Regione Piemonte, EV-ER Piattaforma Tecnologica "Salute e Benessere and POR-FES 2014-2020 - Poli di Innovazione (EPATOCARE), and by the Italian Ministry of Health (IRMI, Italian Regenerative Medicine Infrastructure program CTN01 00177 88744).

\section{Author Disclosure Statement}

The authors declare that no competing financial interests exist.

\section{List of Abbreviations}

$\begin{array}{ll}\text { BMP } & \text { Bone Morphogenetic Protein } \\ \text { BMPER } & \text { Bone Morphogenetic Protein-binding Endothelial Regulator } \\ \text { BMPR } & \text { Bone Morphogenetic Protein Receptor } \\ \text { CLD } & \text { Chronic Liver Disease } \\ \text { EC } & \text { Endothelial Cell } \\ \text { ECM } & \text { Extracellular Matrix } \\ \text { FPN } & \text { Ferroportin } \\ \text { HAMP } & \text { Hepcidin gene } \\ \text { HC } & \text { Hepatocyte } \\ \text { HCV } & \text { Hepatitis C Virus } \\ \text { HGB } & \text { Hemoglobin } \\ \text { HH } & \\ & \end{array}$




\begin{tabular}{|c|c|}
\hline HJV & Hemojuvelin \\
\hline HSC & Hepatic Stellate Cell \\
\hline IRIDA & Iron-Refractory Iron-Deficiency Anemia \\
\hline LMEC & Lung Microvascular Endothelial Cell \\
\hline LSEC & Liver Sinusoidal Endothelial Cell \\
\hline MTP2 & Matriptase-2 \\
\hline NAFLD & Non-Alcoholic Fatty Liver Disease \\
\hline $\mathrm{NASH}$ & Non-Alcoholic Steatohepatitis \\
\hline NGF & Nerve Growth Factor \\
\hline NO & Nitric Oxide \\
\hline NPC & Non-Parenchymal Cell \\
\hline RBC & Red Blood Cell \\
\hline ROS & Reactive Oxygen Species \\
\hline SEM & Scanning Electron Microscopy \\
\hline SNP & Single Nucleotide Polymorphism \\
\hline TGF- $\beta$ & Transforming Growth Factor $\beta$ \\
\hline TFR & Transferrin Receptor \\
\hline TMPRSS6 & Matriptase-2 gene \\
\hline VEGF & Vascular Endothelial Growth Factor \\
\hline
\end{tabular}




\section{References}

1. Abe N, Tsuchida T, Yasuda SI, and Oka K. Dietary iron restriction leads to a reduction in hepatic fibrosis in a rat model of non-alcoholic steatohepatitis. Biol Open 8, 2019.

2. Addo L, Tanaka H, Yamamoto M, Toki Y, Ito S, Ikuta K, Sasaki K, Ohtake T, Torimoto Y, Fujiya M, and Kohgo Y. Hepatic nerve growth factor induced by iron overload triggers defenestration in liver sinusoidal endothelial cells. Biochim Biophys Acta 1852: 175-183, 2015.

3. Altamura S, Schaeper U, Dames S, Löffler K, Eisermann M, Frauendorf C, Müdder K, Neves J, and Muckenthaler MU. SLN124, a GalNAc-siRNA Conjugate Targeting TMPRSS6, Efficiently Prevents Iron Overload in Hereditary Haemochromatosis Type 1. Hemasphere 3: e301, 2019.

4. Andriopoulos B, Corradini E, Xia Y, Faasse SA, Chen S, Grgurevic L, Knutson MD, Pietrangelo A, Vukicevic S, Lin HY, and Babitt JL. BMP6 is a key endogenous regulator of hepcidin expression and iron metabolism. Nat Genet 41: 482-487, 2009.

5. Asrani SK, Devarbhavi H, Eaton J, and Kamath PS. Burden of liver diseases in the world. J Hepatol 70: 151-171, 2019.

6. Augustin HG and Koh GY. Organotypic vasculature: From descriptive heterogeneity to functional pathophysiology. Science 357, 2017.

7. Babitt JL, Huang FW, Wrighting DM, Xia Y, Sidis Y, Samad TA, Campagna JA, Chung RT, Schneyer AL, Woolf CJ, Andrews NC, and Lin HY. Bone morphogenetic protein signaling by hemojuvelin regulates hepcidin expression. Nat Genet 38: 531-539, 2006.

8. Babitt JL, Huang FW, Xia Y, Sidis Y, Andrews NC, and Lin HY. Modulation of bone morphogenetic protein signaling in vivo regulates systemic iron balance. J Clin Invest 117: 19331939, 2007.

9. Baranova A, Lal P, Birerdinc A, and Younossi ZM. Non-invasive markers for hepatic fibrosis. BMC Gastroenterol 11: 91, 2011. 
10. Beneduce E, Matte A, De Falco L, Mbiandjeu S, Chiabrando D, Tolosano E, Federti E, Petrillo S, Mohandas N, Siciliano A, Babu W, Menon V, Ghaffari S, Iolascon A, and De Franceschi L. Fyn kinase is a novel modulator of erythropoietin signaling and stress erythropoiesis. Am J Hematol, 2018.

11. Bloomer SA and Brown KE. Iron-Induced Liver Injury: A Critical Reappraisal. Int J Mol Sci 20, 2019.

12. Blériot $\mathbf{C}$ and Ginhoux F. Understanding the Heterogeneity of Resident Liver Macrophages. Front Immunol 10: 2694, 2019.

13. Braet $\mathbf{F}$ and Wisse $\mathbf{E}$. Structural and functional aspects of liver sinusoidal endothelial cell fenestrae: a review. Comp Hepatol 1: 1, 2002.

14. Bragdon B, Moseychuk O, Saldanha S, King D, Julian J, and Nohe A. Bone morphogenetic proteins: a critical review. Cell Signal 23: 609-620, 2011.

15. Bridle KR, Crawford DH, and Ramm GA. Identification and characterization of the hepatic stellate cell transferrin receptor. Am J Pathol 162: 1661-1667, 2003.

16. Butler JM, Kobayashi H, and Rafii S. Instructive role of the vascular niche in promoting tumour growth and tissue repair by angiocrine factors. Nat Rev Cancer 10: 138-146, 2010.

17. Calès $\mathbf{P}$, Boursier J, Chaigneau J, Oberti F, and Rousselet MC. Treatment of liver fibrosis: clinical aspects. Gastroenterol Clin Biol 33: 958-966, 2009.

18. Canali S, Wang CY, Zumbrennen-Bullough KB, Bayer A, and Babitt JL. Bone morphogenetic protein 2 controls iron homeostasis in mice independent of Bmp6. Am J Hematol 92: 1204-1213, 2017.

19. Canali S, Zumbrennen-Bullough KB, Core AB, Wang CY, Nairz M, Bouley R, Swirski FK, and Babitt JL. Endothelial cells produce bone morphogenetic protein 6 required for iron homeostasis in mice. Blood 129: 405-414, 2017. 
20. Casanovas G, Mleczko-Sanecka K, Altamura S, Hentze MW, and Muckenthaler MU. Bone morphogenetic protein (BMP)-responsive elements located in the proximal and distal hepcidin promoter are critical for its response to HJV/BMP/SMAD. J Mol Med (Berl) 87: 471-480, 2009.

21. Chen J, Chloupková M, Gao J, Chapman-Arvedson TL, and Enns CA. HFE modulates transferrin receptor 2 levels in hepatoma cells via interactions that differ from transferrin receptor 1HFE interactions. J Biol Chem 282: 36862-36870, 2007.

22. Chung JW, Shin E, Kim H, Han HS, Cho JY, Choi YR, Hong S, Jang ES, Kim JW, and Jeong SH. Hepatic iron overload in the portal tract predicts poor survival in hepatocellular carcinoma after curative resection. Liver Int 38: 903-914, 2018.

23. Connolly MK, Bedrosian AS, Malhotra A, Henning JR, Ibrahim J, Vera V, Cieza-Rubio NE, Hassan BU, Pachter HL, Cohen S, Frey AB, and Miller G. In hepatic fibrosis, liver sinusoidal endothelial cells acquire enhanced immunogenicity. J Immunol 185: 2200-2208, 2010.

24. Corradini E, Ferrara F, and Pietrangelo A. Iron and the liver. Pediatr Endocrinol Rev 2 Suppl 2: $245-248,2004$.

25. Crivellato E, Nico B, and Ribatti D. Contribution of endothelial cells to organogenesis: a modern reappraisal of an old Aristotelian concept. J Anat 211: 415-427, 2007.

26. Daher R, Kannengiesser C, Houamel D, Lefebvre T, Bardou-Jacquet E, Ducrot N, de Kerguenec C, Jouanolle AM, Robreau AM, Oudin C, Le Gac G, Moulouel B, Loustaud-Ratti V, Bedossa P, Valla D, Gouya L, Beaumont C, Brissot P, Puy H, Karim Z, and Tchernitchko D. Heterozygous Mutations in BMP6 Pro-peptide Lead to Inappropriate Hepcidin Synthesis and Moderate Iron Overload in Humans. Gastroenterology 150: 672-683.e674, 2016.

27. DeLeve LD. Liver sinusoidal endothelial cells in hepatic fibrosis. Hepatology 61: 1740-1746, 2015.

28. Deleve LD, Wang $\mathbf{X}$, and Guo Y. Sinusoidal endothelial cells prevent rat stellate cell activation and promote reversion to quiescence. Hepatology 48: 920-930, 2008. 
29. DeLeve LD, Wang X, Hu L, McCuskey MK, and McCuskey RS. Rat liver sinusoidal endothelial cell phenotype is maintained by paracrine and autocrine regulation. Am J Physiol Gastrointest Liver Physiol 287: G757-763, 2004.

30. Delgado I, Carrasco M, Cano E, Carmona R, García-Carbonero R, Marín-Gómez LM, Soria B, Martín F, Cano DA, Muñoz-Chápuli R, and Rojas A. GATA4 loss in the septum transversum mesenchyme promotes liver fibrosis in mice. Hepatology 59: 2358-2370, 2014.

31. Di Bisceglie AM, Axiotis CA, Hoofnagle JH, and Bacon BR. Measurements of iron status in patients with chronic hepatitis. Gastroenterology 102: 2108-2113, 1992.

32. Ding BS, Cao Z, Lis R, Nolan DJ, Guo P, Simons M, Penfold ME, Shido K, Rabbany SY, and Rafii S. Divergent angiocrine signals from vascular niche balance liver regeneration and fibrosis. Nature 505: 97-102, 2014.

33. Du Y, Li N, Yang H, Luo C, Gong Y, Tong C, Gao Y, Lü S, and Long M. Mimicking liver sinusoidal structures and functions using a 3D-configured microfluidic chip. Lab Chip 17: 782-794, 2017.

34. Duan JL, Ruan B, Yan XC, Liang L, Song P, Yang ZY, Liu Y, Dou KF, Han H, and Wang L. Endothelial Notch activation reshapes the angiocrine of sinusoidal endothelia to aggravate liver fibrosis and blunt regeneration in mice. Hepatology 68: 677-690, 2018.

35. Duarte TL, Caldas C, Santos AG, Silva-Gomes S, Santos-Gonçalves A, Martins MJ, Porto G, and Lopes JM. Genetic disruption of NRF2 promotes the development of necroinflammation and liver fibrosis in a mouse model of HFE-hereditary hemochromatosis. Redox Biol 11: 157-169, 2017. 36. Duncan AW, Dorrell C, and Grompe M. Stem cells and liver regeneration. Gastroenterology 137: 466-481, 2009.

37. Détivaud L, Nemeth E, Boudjema K, Turlin B, Troadec MB, Leroyer P, Ropert M, Jacquelinet S, Courselaud B, Ganz T, Brissot P, and Loréal O. Hepcidin levels in humans are correlated with hepatic iron stores, hemoglobin levels, and hepatic function. Blood 106: 746-748, 2005. 
38. Ellis EL and Mann DA. Clinical evidence for the regression of liver fibrosis. J Hepatol 56: 1171-1180, 2012.

39. Finberg KE, Heeney MM, Campagna DR, Aydinok Y, Pearson HA, Hartman KR, Mayo MM, Samuel SM, Strouse JJ, Markianos K, Andrews NC, and Fleming MD. Mutations in TMPRSS6 cause iron-refractory iron deficiency anemia (IRIDA). Nat Genet 40: 569-571, 2008.

40. Fix OK and Kowdley KV. Hereditary hemochromatosis. Minerva Med 99: 605-617, 2008.

41. Ford AJ, Jain G, and Rajagopalan P. Designing a fibrotic microenvironment to investigate changes in human liver sinusoidal endothelial cell function. Acta Biomater 24: 220-227, 2015.

42. Ganz T. Hepcidin, a key regulator of iron metabolism and mediator of anemia of inflammation. Blood 102: 783-788, 2003.

43. Gao J, Chen J, Kramer M, Tsukamoto H, Zhang AS, and Enns CA. Interaction of the hereditary hemochromatosis protein HFE with transferrin receptor 2 is required for transferrininduced hepcidin expression. Cell Metab 9: 217-227, 2009.

44. George DK, Goldwurm S, MacDonald GA, Cowley LL, Walker NI, Ward PJ, Jazwinska EC, and Powell LW. Increased hepatic iron concentration in nonalcoholic steatohepatitis is associated with increased fibrosis. Gastroenterology 114: 311-318, 1998.

45. Goveia J, Stapor P, and Carmeliet P. Principles of targeting endothelial cell metabolism to treat angiogenesis and endothelial cell dysfunction in disease. EMBO Mol Med 6: 1105-1120, 2014. 46. Gracia-Sancho J, Laviña B, Rodríguez-Vilarrupla A, García-Calderó H, Bosch J, and GarcíaPagán JC. Enhanced vasoconstrictor prostanoid production by sinusoidal endothelial cells increases portal perfusion pressure in cirrhotic rat livers. J Hepatol 47: 220-227, 2007.

47. Greuter T and Shah VH. Hepatic sinusoids in liver injury, inflammation, and fibrosis: new pathophysiological insights. J Gastroenterol 51: 511-519, 2016.

48. Gruys E, Toussaint MJ, Niewold TA, and Koopmans SJ. Acute phase reaction and acute phase proteins. J Zhejiang Univ Sci B 6: 1045-1056, 2005. 
49. Géraud C, Koch PS, Zierow J, Klapproth K, Busch K, Olsavszky V, Leibing T, Demory A, Ulbrich F, Diett M, Singh S, Sticht C, Breitkopf-Heinlein K, Richter K, Karppinen SM, Pihlajaniemi T, Arnold B, Rodewald HR, Augustin HG, Schledzewski K, and Goerdt S. GATA4-dependent organspecific endothelial differentiation controls liver development and embryonic hematopoiesis. J Clin Invest 127: 1099-1114, 2017.

50. Géraud C, Schledzewski K, Demory A, Klein D, Kaus M, Peyre F, Sticht C, Evdokimov K, Lu S, Schmieder A, and Goerdt S. Liver sinusoidal endothelium: a microenvironment-dependent differentiation program in rat including the novel junctional protein liver endothelial differentiationassociated protein-1. Hepatology 52: 313-326, 2010.

51. Hammoutene A and Rautou PE. Role of liver sinusoidal endothelial cells in non-alcoholic fatty liver disease. J Hepatol 70: 1278-1291, 2019.

52. Hasebe T, Tanaka H, Sawada K, Nakajima S, Ohtake T, Fujiya M, and Kohgo Y. Bone morphogenetic protein-binding endothelial regulator of liver sinusoidal endothelial cells induces iron overload in a fatty liver mouse model. J Gastroentero/ 52: 341-351, 2017.

53. Hentze MW, Muckenthaler MU, Galy B, and Camaschella C. Two to tango: regulation of Mammalian iron metabolism. Cell 142: 24-38, 2010.

54. Hwa AJ, Fry RC, Sivaraman A, So PT, Samson LD, Stolz DB, and Griffith LG. Rat liver sinusoidal endothelial cells survive without exogenous VEGF in 3D perfused co-cultures with hepatocytes. FASEB J 21: 2564-2579, 2007.

55. Ikoma N, Shinozaki H, Kozuki A, Ibuki S, Sugano K, Mukai M, Masuda Y, Kobayashi K, and Ogata Y. A Case Report of Hepatocellular Carcinoma in a Non-cirrhotic Patient With Liver Iron Overload Associated With Myelodysplastic Syndrome. World J Oncol 4: 248-251, 2013.

56. Isaacs MJ, Kawakami Y, Allendorph GP, Yoon BH, Izpisua Belmonte JC, and Choe S. Bone morphogenetic protein-2 and -6 heterodimer illustrates the nature of ligand-receptor assembly. $\mathrm{Mol}$ Endocrinol 24: 1469-1477, 2010. 
57. Katsarou MS, Papasavva M, Latsi R, and Drakoulis N. Hemochromatosis: Hereditary hemochromatosis and HFE gene. Vitam Horm 110: 201-222, 2019.

58. Kmieć Z. Cooperation of liver cells in health and disease. Adv Anat Embryol Cell Biol 161: IIIXIII, 1-151, 2001.

59. Knorr A, Hirth-Dietrich C, Alonso-Alija C, Härter M, Hahn M, Keim Y, Wunder F, and Stasch JP. Nitric oxide-independent activation of soluble guanylate cyclase by BAY 60-2770 in experimental liver fibrosis. Arzneimittelforschung 58: 71-80, 2008.

60. Ko C, Siddaiah N, Berger J, Gish R, Brandhagen D, Sterling RK, Cotler SJ, Fontana RJ, McCashland TM, Han SH, Gordon FD, Schilsky ML, and Kowdley KV. Prevalence of hepatic iron overload and association with hepatocellular cancer in end-stage liver disease: results from the National Hemochromatosis Transplant Registry. Liver Int 27: 1394-1401, 2007.

61. Koch PS, Olsavszky V, Ulbrich F, Sticht C, Demory A, Leibing T, Henzler T, Meyer M, Zierow J, Schneider S, Breitkopf-Heinlein K, Gaitantzi H, Spencer-Dene B, Arnold B, Klapproth K, Schledzewski K, Goerdt S, and Géraud C. Angiocrine Bmp2 signaling in murine liver controls normal iron homeostasis. Blood 129: 415-419, 2017.

62. Kovac S, Böser P, Cui Y, Ferring-Appel D, Casarrubea D, Huang L, Fung E, Popp A, Mueller BK, and Hentze MW. Anti-hemojuvelin antibody corrects anemia caused by inappropriately high hepcidin levels. Haematologica 101: e173-176, 2016.

63. Kowdley KV. Iron Overload in Patients With Chronic Liver Disease. Gastroenterol Hepatol (N Y) 12: 695-698, 2016.

64. Kowdley KV, Brandhagen DJ, Gish RG, Bass NM, Weinstein J, Schilsky ML, Fontana RJ, McCashland T, Cotler SJ, Bacon BR, Keeffe EB, Gordon F, Polissar N, and Registry NHT. Survival after liver transplantation in patients with hepatic iron overload: the national hemochromatosis transplant registry. Gastroenterology 129: 494-503, 2005. 
65. Lammert E, Cleaver $\mathbf{O}$, and Melton $\mathrm{D}$. Induction of pancreatic differentiation by signals from blood vessels. Science 294: 564-567, 2001.

66. Latour C, Besson-Fournier C, Gourbeyre O, Meynard D, Roth MP, and Coppin H. Deletion of BMP6 worsens the phenotype of HJV-deficient mice and attenuates hepcidin levels reached after LPS challenge. Blood 130: 2339-2343, 2017.

67. Latour C, Besson-Fournier C, Meynard D, Silvestri L, Gourbeyre O, Aguilar-Martinez P, Schmidt PJ, Fleming MD, Roth MP, and Coppin H. Differing impact of the deletion of hemochromatosis-associated molecules HFE and transferrin receptor- 2 on the iron phenotype of mice lacking bone morphogenetic protein 6 or hemojuvelin. Hepatology 63: 126-137, 2016.

68. Leach HG, Chrobak I, Han R, and Trojanowska M. Endothelial cells recruit macrophages and contribute to a fibrotic milieu in bleomycin lung injury. Am J Respir Cell Mol Biol 49: 1093-1101, 2013.

69. Lee SH, Jeong SH, Park YS, Hwang JH, Kim JW, Kim N, and Lee DH. Serum prohepcidin levels in chronic hepatitis C, alcoholic liver disease, and nonalcoholic fatty liver disease. Korean J Hepatol 16: 288-294, 2010.

70. Lim PJ, Duarte TL, Arezes J, Garcia-Santos D, Hamdi A, Pasricha SR, Armitage AE, Mehta H, Wideman S, Santos AG, Santos-Gonçalves A, Morovat A, Hughes JR, Soilleux E, Wang CY, Bayer AL, Klenerman P, Willberg CB, Hartley RC, Murphy MP, Babitt JL, Ponka P, Porto G, and Drakesmith H. Nrf2 controls iron homeostasis in haemochromatosis and thalassaemia via Bmp6 and hepcidin. Nat Metab 1: 519-531, 2019.

71. Lin L, Valore EV, Nemeth E, Goodnough JB, Gabayan V, and Ganz T. Iron transferrin regulates hepcidin synthesis in primary hepatocyte culture through hemojuvelin and BMP2/4. Blood 110: 2182-2189, 2007.

72. March S, Hui EE, Underhill GH, Khetani S, and Bhatia SN. Microenvironmental regulation of the sinusoidal endothelial cell phenotype in vitro. Hepatology 50: 920-928, 2009. 
73. Marcu R, Choi YJ, Xue J, Fortin CL, Wang Y, Nagao RJ, Xu J, MacDonald JW, Bammler TK, Murry CE, Muczynski K, Stevens KR, Himmelfarb J, Schwartz SM, and Zheng Y. Human OrganSpecific Endothelial Cell Heterogeneity. iScience 4: 20-35, 2018.

74. Martinez-Hernandez A and Martinez J. The role of capillarization in hepatic failure: studies in carbon tetrachloride-induced cirrhosis. Hepatology 14: 864-874, 1991.

75. Massagué J and Gomis RR. The logic of TGFbeta signaling. FEBS Lett 580: 2811-2820, 2006.

76. Massagué J, Seoane J, and Wotton D. Smad transcription factors. Genes Dev 19: 2783-2810, 2005.

77. Matsumoto K, Yoshitomi H, Rossant J, and Zaret KS. Liver organogenesis promoted by endothelial cells prior to vascular function. Science 294: 559-563, 2001.

78. May D, Djonov V, Zamir G, Bala M, Safadi R, Sklair-Levy M, and Keshet E. A transgenic model for conditional induction and rescue of portal hypertension reveals a role of VEGF-mediated regulation of sinusoidal fenestrations. PLoS One 6: e21478, 2011.

79. McGuire RF, Bissell DM, Boyles J, and Roll FJ. Role of extracellular matrix in regulating fenestrations of sinusoidal endothelial cells isolated from normal rat liver. Hepatology 15: 989-997, 1992.

80. McMahan RH, Porsche CE, Edwards MG, and Rosen HR. Free Fatty Acids Differentially Downregulate Chemokines in Liver Sinusoidal Endothelial Cells: Insights into Non-Alcoholic Fatty Liver Disease. PLoS One 11: e0159217, 2016.

81. Mehta KJ, Coombes JD, Briones-Orta M, Manka PP, Williams R, Patel VB, and Syn WK. Iron Enhances Hepatic Fibrogenesis and Activates Transforming Growth Factor- $\beta$ Signaling in Murine Hepatic Stellate Cells. Am J Med Sci 355: 183-190, 2018.

82. Mehta KJ, Farnaud SJ, and Sharp PA. Iron and liver fibrosis: Mechanistic and clinical aspects. World J Gastroenterol 25: 521-538, 2019. 
83. Milet J, Le Gac G, Scotet V, Gourlaouen I, Thèze C, Mosser J, Bourgain C, Deugnier Y, and Férec C. A common SNP near BMP2 is associated with severity of the iron burden in HFE p.C282Y homozygous patients: a follow-up study. Blood Cells Mol Dis 44: 34-37, 2010.

84. Miyao M, Kotani H, Ishida T, Kawai C, Manabe S, Abiru H, and Tamaki K. Pivotal role of liver sinusoidal endothelial cells in NAFLD/NASH progression. Lab Invest 95: 1130-1144, 2015.

85. Miyao M, Ozeki M, Abiru H, Manabe S, Kotani H, Tsuruyama T, and Tamaki K. Bile canalicular abnormalities in the early phase of a mouse model of sclerosing cholangitis. Dig Liver Dis 45: 216-225, 2013.

86. Muckenthaler MU, Rivella S, Hentze MW, and Galy B. A Red Carpet for Iron Metabolism. Cell 168: 344-361, 2017.

87. Nai A, Rubio A, Campanella A, Gourbeyre O, Artuso I, Bordini J, Gineste A, Latour C, Besson-Fournier C, Lin HY, Coppin H, Roth MP, Camaschella C, Silvestri L, and Meynard D. Limiting hepatic Bmp-Smad signaling by matriptase-2 is required for erythropoietin-mediated hepcidin suppression in mice. Blood 127: 2327-2336, 2016.

88. Natarajan V, Harris EN, and Kidambi S. SECs (Sinusoidal Endothelial Cells), Liver Microenvironment, and Fibrosis. Biomed Res Int 2017: 4097205, 2017.

89. Nemeth E, Tuttle MS, Powelson J, Vaughn MB, Donovan A, Ward DM, Ganz T, and Kaplan J. Hepcidin regulates cellular iron efflux by binding to ferroportin and inducing its internalization. Science 306: 2090-2093, 2004.

90. Ni Y, Li JM, Liu MK, Zhang TT, Wang DP, Zhou WH, Hu LZ, and Lv WL. Pathological process of liver sinusoidal endothelial cells in liver diseases. World J Gastroenterol 23: 7666-7677, 2017.

91. Nicolas G, Viatte L, Bennoun M, Beaumont C, Kahn A, and Vaulont S. Hepcidin, a new iron regulatory peptide. Blood Cells Mol Dis 29: 327-335, 2002.

92. Nolan DJ, Ginsberg M, Israely E, Palikuqi B, Poulos MG, James D, Ding BS, Schachterle W, Liu Y, Rosenwaks Z, Butler JM, Xiang J, Rafii A, Shido K, Rabbany SY, Elemento O, and Rafii S. 
Molecular signatures of tissue-specific microvascular endothelial cell heterogeneity in organ maintenance and regeneration. Dev Cell 26: 204-219, 2013.

93. Ogawa K, Minase T, Enomoto K, and Onoé T. Ultrastructure of fenestrated cells in the sinusoidal wall of rat liver after perfusion fixation. Tohoku J Exp Med 110: 89-101, 1973.

94. Olsavszky V, Ulbrich F, Singh S, Diett M, Sticht C, Schmid CD, Zierow J, Wohlfeil SA, Schledzewski K, Dooley S, Gaitantzi H, Breitkopf-Heinlein K, Géraud C, Goerdt S, and Koch PS. GATA4 and LMO3 balance angiocrine signaling and autocrine inflammatory activation by BMP2 in liver sinusoidal endothelial cells. Gene 627: 491-499, 2017.

95. Park CH, Valore EV, Waring AJ, and Ganz T. Hepcidin, a urinary antimicrobial peptide synthesized in the liver. J Biol Chem 276: 7806-7810, 2001.

96. Parrow NL and Fleming RE. Bone morphogenetic proteins as regulators of iron metabolism. Annu Rev Nutr 34: 77-94, 2014.

97. Parrow NL and Fleming RE. Liver sinusoidal endothelial cells as iron sensors. Blood 129: 397398, 2017.

98. Patel N, Masaratana P, Diaz-Castro J, Latunde-Dada GO, Qureshi A, Lockyer P, Jacob M, Arno M, Matak P, Mitry RR, Hughes RD, Dhawan A, Patterson C, Simpson RJ, and McKie AT. BMPER protein is a negative regulator of hepcidin and is up-regulated in hypotransferrinemic mice. J Biol Chem 287: 4099-4106, 2012.

99. Pietrangelo A. Iron-induced oxidant stress in alcoholic liver fibrogenesis. Alcohol 30: 121129, 2003.

100. Pigeon C, llyin G, Courselaud B, Leroyer P, Turlin B, Brissot P, and Loréal O. A new mouse liver-specific gene, encoding a protein homologous to human antimicrobial peptide hepcidin, is overexpressed during iron overload. J Biol Chem 276: 7811-7819, 2001.

101. Poisson J, Lemoinne S, Boulanger C, Durand F, Moreau R, Valla D, and Rautou PE. Liver sinusoidal endothelial cells: Physiology and role in liver diseases. J Hepatol 66: 212-227, 2017. 
102. Ramm GA, Britton RS, O'Neill R, and Bacon BR. Identification and characterization of a receptor for tissue ferritin on activated rat lipocytes. J Clin Invest 94: 9-15, 1994.

103. Ramm GA and Ruddell RG. Hepatotoxicity of iron overload: mechanisms of iron-induced hepatic fibrogenesis. Semin Liver Dis 25: 433-449, 2005.

104. Rausa M, Pagani A, Nai A, Campanella A, Gilberti ME, Apostoli P, Camaschella C, and Silvestri L. Bmp6 expression in murine liver non parenchymal cells: a mechanism to control their high iron exporter activity and protect hepatocytes from iron overload? PLoS One 10: e0122696, 2015.

105. Rockey DC and Chung JJ. Reduced nitric oxide production by endothelial cells in cirrhotic rat liver: endothelial dysfunction in portal hypertension. Gastroenterology 114: 344-351, 1998.

106. Ruart M, Chavarria L, Campreciós G, Suárez-Herrera N, Montironi C, Guixé-Muntet S, Bosch J, Friedman SL, Garcia-Pagán JC, and Hernández-Gea V. Impaired endothelial autophagy promotes liver fibrosis by aggravating the oxidative stress response during acute liver injury. J Hepatol 70: 458469, 2019.

107. SCHAFFNER F and POPER H. Capillarization of hepatic sinusoids in man. Gastroenterology 44: 239-242, 1963.

108. Schmid CD, Schledzewski K, Mogler C, Waldburger N, Kalna V, Marx A, Randi AM, Géraud C, Goerdt S, and Koch PS. GPR182 is a novel marker for sinusoidal endothelial differentiation with distinct GPCR signaling activity in vitro. Biochem Biophys Res Commun 497: 32-38, 2018.

109. Sibille JC, Kondo H, and Aisen P. Interactions between isolated hepatocytes and Kupffer cells in iron metabolism: a possible role for ferritin as an iron carrier protein. Hepatology 8: 296-301, 1988.

110. Sørensen KK, McCourt P, Berg T, Crossley C, Le Couteur D, Wake K, and Smedsrød B. The scavenger endothelial cell: a new player in homeostasis and immunity. Am J Physiol Regul Integr Comp Physiol 303: R1217-1230, 2012. 
111. Tacke F and Trautwein C. Mechanisms of liver fibrosis resolution. J Hepatol 63: 1038-1039, 2015.

112. Tolosano E, Fagoonee S, Morello N, Vinchi F, and Fiorito V. Heme scavenging and the other facets of hemopexin. Antioxid Redox Signal 12: 305-320, 2010.

113. Torti FM and Torti SV. Regulation of ferritin genes and protein. Blood 99: 3505-3516, 2002.

114. Tsochatzis E, Papatheodoridis GV, Koliaraki V, Hadziyannis E, Kafiri G, Manesis EK, Mamalaki A, and Archimandritis AJ. Serum hepcidin levels are related to the severity of liver histological lesions in chronic hepatitis C. J Viral Hepat 17: 800-806, 2010.

115. Tugues S, Morales-Ruiz M, Fernandez-Varo G, Ros J, Arteta D, Muñoz-Luque J, Arroyo V, Rodés J, and Jiménez W. Microarray analysis of endothelial differentially expressed genes in liver of cirrhotic rats. Gastroenterology 129: 1686-1695, 2005.

116. Wang RH, Li C, Xu X, Zheng Y, Xiao C, Zerfas P, Cooperman S, Eckhaus M, Rouault T, Mishra L, and Deng CX. A role of SMAD4 in iron metabolism through the positive regulation of hepcidin expression. Cell Metab 2: 399-409, 2005.

117. Weiss A and Attisano L. The TGFbeta superfamily signaling pathway. Wiley Interdiscip Rev Dev Biol 2: 47-63, 2013.

118. Widmann JJ and Fahimi HD. Proliferation of mononuclear phagocytes (Kupffer cells) and endothelial cells in regenerating rat liver. A light and electron microscopic cytochemical study. Am J Pathol 80: 349-366, 1975.

119. Wisse E. An electron microscopic study of the fenestrated endothelial lining of rat liver sinusoids. J Ultrastruct Res 31: 125-150, 1970.

120. Wisse E. An ultrastructural characterization of the endothelial cell in the rat liver sinusoid under normal and various experimental conditions, as a contribution to the distinction between endothelial and Kupffer cells. J Ultrastruct Res 38: 528-562, 1972. 
121. Wisse E, De Zanger RB, Jacobs R, and McCuskey RS. Scanning electron microscope observations on the structure of portal veins, sinusoids and central veins in rat liver. Scan Electron Microsc: 1441-1452, 1983.

122. Xiao X, Dev S, Canali S, Bayer A, Xu Y, Agarwal A, Wang CY, and Babitt JL. Endothelial Bmp2 knockout exacerbates hemochromatosis in Hfe knockout mice but not Bmp6 knockout mice. Hepatology, 2019.

123. Xie G, Wang L, Wang X, and DeLeve LD. Isolation of periportal, midlobular, and centrilobular rat liver sinusoidal endothelial cells enables study of zonated drug toxicity. Am J Physiol Gastrointest Liver Physiol 299: G1204-1210, 2010.

124. Xie G, Wang X, Wang L, Atkinson RD, Kanel GC, Gaarde WA, and Deleve LD. Role of differentiation of liver sinusoidal endothelial cells in progression and regression of hepatic fibrosis in rats. Gastroenterology 142: 918-927.e916, 2012.

125. Xu B, Broome U, Uzunel M, Nava S, Ge X, Kumagai-Braesch M, Hultenby K, Christensson B, Ericzon BG, Holgersson J, and Sumitran-Holgersson S. Capillarization of hepatic sinusoid by liver endothelial cell-reactive autoantibodies in patients with cirrhosis and chronic hepatitis. Am J Pathol 163: 1275-1289, 2003.

126. Xu M, Wang X, Zou Y, and Zhong Y. Key role of liver sinusoidal endothelial cells in liver fibrosis. Biosci Trends 11: 163-168, 2017.

127. Zhang AS, Anderson SA, Wang J, Yang F, DeMaster K, Ahmed R, Nizzi CP, Eisenstein RS, Tsukamoto H, and Enns CA. Suppression of hepatic hepcidin expression in response to acute iron deprivation is associated with an increase of matriptase-2 protein. Blood 117: 1687-1699, 2011. 128. Zhang F, Zhang Z, Chen L, Kong D, Zhang X, Lu C, Lu Y, and Zheng S. Curcumin attenuates angiogenesis in liver fibrosis and inhibits angiogenic properties of hepatic stellate cells. J Cell Mol Med 18: 1392-1406, 2014. 


\section{Figure legends}

Figure 1. Schematic representation of the cellular events that occur when a pro-fibrotic stimulus persists over time. LSEC, Liver Sinusoidal Endothelial Cell; HSC, Hepatic Stellate Cell; HC, Hepatocyte.

Figure 2. Schematic representation of the harmful effects mediated by iron on liver cell populations. Iron overload induces oxidative damage in Kupffer cells and Hepatocytes, which in turn release a repertoire of pro-inflammatory and pro-fibrogenic factors. These factors promote the activation of HSCs, an early events in the fibrotic process. Ironmediated cellular damage is then perpetuated over time and also affects HSCs that, once activated, express TFR1 on their surface. HSC, Hepatic Stellate Cell; TFR1, Transferrin Receptor 1; TSAT, transferrin saturation.

Figure 3. Schematic represention of structural differences between normal and cirrhotic sinusoidal milieu. In normal liver (top), the presence of open fenestrae and the lack of basement membran allow a bidirectional exchange between blood and the space of Disse, where reside quiescent HSCs. In the fibrotic liver (bottom), there is the deposition of an organized basement membrane along the sinusoids, the loss of LSECs fenestrae and the activation of HSCs, which in turn cause excessive collagen deposition whithin the space of Disse.

Figure 4. The liver-secreted peptide hormone hepcidin is a master regulator of iron homeostasis. hepcidin, by promoting the internalization of the iron exporter Ferroportin on target cells, determines the amount of iron that is released into circulation. FPN, Ferroportin; Fe, Iron; HGB, Hemoglobin.

Figure 5. LSECs are the major source of BMPs. Once released by LSECs, BMPs bind to their receptors expressed on the hepatocyte. The signal transduction involves SMAD proteins, which drive the transcription of HAMP gene. BMP-SMAD signaling pathway 
requires the presence on hepatocytes surface of the co-receptor HJV. Hepcidin induction is inhibited by the serine protease MTP2, that is indeed able to cleave HJV. BMP, Bone Morphogenetic Protein; BMPR, BMP Receptor; HJV, Hemojuvelin; MTP2, Matriptase-2; HAMP, Hepcidin gene.

Figure 6. In the fibrotic liver, iron dysregulation and LSECs capillarization likely synergize to instaure a vicious loop that exhacerbates the progression of fibrosis. De-differentiated LSECs release high levels of BMPER and low levels of BMP2, thus inhibiting hepcidin production by the hepatocytes. Hepcidin inhibition results in iron overload. Iron overload induces the release of NGF by hepatocytes, a growth factor able to promote LSECs capillarization, thus sustaining the detrimental cycle. LSECs, Liver Sinusoidal Endothelial Cells; NGF, Nerve Growth Factor; BMPER, BMP-binding Endothelial Regulator; BMP2, Bone Morphogenetic Protein 2; Fe, Iron. 